trang thái mêt mỏi $(95 \% \mathrm{CI}=1,0-4,4)$; có điểm kiểm soát nguy cơ không tốt cao gấp 3,4 lần so với nhóm có điểm kiểm soát nguy cơ tốt $(95 \% C I=1,6-7,2)$; điểm kiên nhẫn khi lái xe không tốt cao gấp 4,7 lần so với nhóm có điểm kiên nhẫn khi lái xe tốt $(95 \% \mathrm{CI}=2,0-11,3)$.

\section{KHUYẾN NGH!}

Các tác giả khuyến nghị cần áp dụng giải pháp kiểm soát hành vi của lái xe góp phần giảm thiểu tai nạn giao thông.

\section{TÀI LIÊU THAM KHẢO}

1. Alavi SS, Mohammadi M, Soori H et al (2016). Iranian Version of Manchester Driving Behavior Questionnaire (MDBQ): Psychometric Properties. Iran J Psychiatry. 2016 Jan; 11(1):37-42

2. Bener A, Verjee M, Dafeeah EE, Yousafzai MT et al (2013). A cross "ethnical" comparison of the Driver Behaviour Questionnaire (DBQ) in an economically fast developing country. Glob J Health Sci. 2013 May 12;5(4):165-75

3. Kamari Ghanavati $F$, Jahangiri $\mathbf{M}$, Khalifeh $\mathbf{M}$ et al (2018). "The effect of biological rhythms and personality traits on the incidence of unsafe behaviors among bus drivers in Shiraz, Iran". J Inj Violence Res. 2018 Jan;10(1):3-10.

4. Koppel S, Stephens AN, Charlton JL et al (2018). "The Driver Behaviour Questionnaire for older drivers: Do errors, violations and lapses change over time?". Accid Anal Prev. 2018 Feb 5;113:171-178.

5. Pourabdian S, Azmoon H (2013). The Relationship between Trait Anxiety and Driving Behavior with Regard to Self-reported Iranian Accident Involving Drivers. Int J Prev Med. 2013 Oct; 4(10):1115-21.

6. Qu W, Zhang Q, Zhao W et al (2016), Validation of the Driver Stress Inventory in China: Relationship with dangerous driving behaviors, Accid Anal Prev. 2016 Feb;87:50-8. Epub 2015 Nov 29.

\title{
KẾT QUẢ PHẪU THUÂTT NộI SOI CHİNH HÌNH VÁCH NGĂN MŨI CÓ SỬ DỤNG MEROCEL CÓ ỐNG THÔNG
}

\section{TÓM TẮT}

Muc tiêu nghiên cứu: Kết quả phẫu thuật nội soi chỉnh hình vách ngăn mũi có sử dụng Merocel có ống thông. Thiết kế nghiên cứu: tiến cứu. Nơi thực hiện: Bệnh viện đại học y Hà Nội từ 9/2020 đển 8/2021. Đối tương: 23 bênh nhân được chẩn đoán là dị hình vách ngẳn, được phẫu thuật nội soi chỉnh hình vách ngăn mữi có sử dụng merocel có ống thong. Kết quả: Sau phẫu thuật 24h, 23/23 bệnh nhân thở được qua merocel có ống thông, đau hổc mổ gắp ở 19/23 bệnh nhân với điểm VAS trung bình là $2.78 \pm 1.88$. Không có bênh nhân nào mất ngửi, đau tai, ù tai. Không có bệnh nhân nào có biến chứng tụ máu vách ngăn, nhiếm trùng, có 1 bệnh nhân chảy máu ngay sau phẫu thuật chiếm tỉ lệ $4.3 \%$. Kết luận: Nội soi chỉnh hình vách ngăn có sử dụng merocel có ống thông đạt được kết quả tốt, bệnh nhân có thể thở bằng mũi qua ống thông, do vậy làm giảm các triệu chứng khó chịu (đau đâu, ho, ù tai...) giúp nâng cao chất lượng điều trì cho bệnh nhân.

Tư khóa: phẫu thuật chỉnh hình vách ngăn mũi, merocel mũi có ống thông,

\section{SUMMARY}

\section{RESULTS OF ENDOSCOPY SEPTOPLASTY}

\author{
${ }^{1}$ Bệnh viện trường Đại học Kỹ thuật y tế Hải Dương \\ 2Bềnh viện Đại học Y Hà Nôi \\ Chịu trách nhiệm chính: Trần Văn Minh \\ Email: hoangtuhmu@gmail.com \\ Ngày nhận bài: 4.6.2021 \\ Ngày phản biên khoa hoc: 27.7.2021 \\ Ngày duyệt bài: 5.8 .2021
}

\section{Trần Văn Minh¹, Cao Minh Thành² \\ USE MEROCEL WITH AIRWWAY}

Objective: Results of endoscopic septoplasty using merocel with airway. Study design: Prospective study. Setting: In $\mathrm{Ha}$ Noi medical university Hospital. Patients: 23 patients having nasal septum deviation were endoscopic septoplasty using merocel with airway. Results: 24 hours after surgery, $23 / 23$ patients breathe well through merocel with airway. The mean scores of nasal pain was $2.78 \pm$ 1.88. No patient loss of smell, ear pain and tinnitus. In the retainer group, the incidence of grade 1 bleeding was $4.3 \%$, no patient had an infection, heamatoma and septal perforation. Conclusion : Results of endoscopic septoplasty using merocel with airway is good without complication

Key words; septoplasty, merocel with airway.

\section{I. ĐẶT VẤN ĐỀ}

Di hình vách ngăn mũi là môt bênh lý thường gặp ở người Việt Nam. Dị hình vách ngăn mũi có thể gặp là: lệch, vẹo, mào, gai hoặc dày chân vách ngăn mà nguyên nhân do sự phát triển bất thường của vách ngăn mũi hoặc các khối xương có liên quan, do chấn thương ${ }^{i}$. Hậu quả của di hình vách ngăn thường gây hẹp hốc mũi bên di hình, cản trở thông khí, giảm thông khí. Biểu hiện lâm sàng khác nhau ở mỗi người, mỗi loại dị hình và mức độ dị hình, có thể là yếu tố thuận lợi trong bệnh viêm mũi xoang, hoặc gây viêm mũi xoang kéo dài. Chỉnh hình vách ngăn có rất nhiều kỹ thuật và phương pháp, phương pháp phổ biến hiện nay là phẩu thuật nội soi chỉnh 
hình vách ngăn mũi ${ }^{2}$. Merocel là vật liệu phổ biến dùng cho bệnh nhân sau phẫu thuật, giúp định hình lại vách ngăn mũi, hạn chế chảy máu và biến chứng sau mổ. Thời gian gần đây phát triển loại merocel mũi mới là merocel có ống thông, tuy nhiên chưa có nghiên cứu nào chỉ ra được ưu, nhược điểm của loại merocel này, vì vậy nghiên cứu này được tiến hành với mục tiêuu chính: Đánh giá kết quả phẫu thuật nội soi chỉnh hinh vách mũi có sư dụng merocel có ống thông.

\section{II. ĐỐI TƯợNG VÀ PHƯƠNG PHÁP NGHIÊN CỨU \\ 2.1 Đối tượng nghiên cứu}

- Những bệnh nhân được chẩn đoán là dị hình vách ngăn. Được khám và điều trị tại bệnh viện đại học y Hà Nội từ 9/2020 đến 8/2021.

- Số lượng bệnh nhân: 23

- Tiêu chuấn chơn bệnh nhân

+ Khám nội soi chẩn đoán là dị hình vách ngăn

+ Phẫu thuật: nội soi chỉnh hình vách ngăn bằng khoan hummer

+ Sử dụng merocel có ống thông trong phẫu thuật

+ Đánh giá chức năng thông khí mũi bằng gương Glatzel sau FT 24h

+ Bệnh nhân đồng ý tham gia nghiên cứu trên

- Tiêu chuâin loại trừ: không đủ tiêu chuẩn

\subsection{Phương pháp nghiên cứu}

- Nghiên cứu tiến cứu có can thiệp

- Phương tiện nghiên cứu

+ Bộ nội soi, phấu thuật Karlstortz của Đức

+ Khoan hummer, bộ mũi khoan cắt và kim cương.

- So sánh trước và ngay sau phẫu thuật, sau phẫu thuật 1 tháng.

- Xử lý số liệu bằng SPSS 16.0.

\section{KẾT QUẢ NGHIÊN CứU}

\subsection{Tuổi và giới}

- Nhóm tuổi hay gặp nhất từ 25-35 tuổi (15 bệnh nhân), tuổi nhỏ nhất là 18 , tuổi lớn nhất là 38 tuổi,

- Giới : tỷ lệ Nam/Nũ̃ =3.6

\subsection{Triệu chứng lâm sàng}

3.2.1. Triệu chứng cơ năng

Bảng 3.1: Tỷ lệ các triệu chứng lâm sàng

\begin{tabular}{|c|c|c|}
\hline Triệu chứng (n=23) & $\mathbf{n}$ & $\mathbf{\%}$ \\
\hline Ngạt mũi & 21 & 91,3 \\
\hline Hắt hơi & 19 & 82,6 \\
\hline Chảy mũi & 18 & 78.2 \\
\hline Đau đâu & 8 & 34,7 \\
\hline
\end{tabular}

Nhận xét: Triệu chứng ngạt mũi chiếm cao nhất với $91.3 \%$, chảy mũi chiếm tỉ lệ $78.2 \%$, hắt hơi chiếm $82,6 \%$, đau đầu chiếm tỷ lệ thấp nhất là 34,7\%. Sự khác biệt giữa các triệu chứng có ý nghĩa thống kê với $p<0.05$.

\subsubsection{Triệu chứng thức thể}

Bảng 3.2: Tỷ lể loai dị hình vách ngăn

\begin{tabular}{|c|c|c|}
\hline Loại dị hình vách ngăn & $\mathbf{N = 2 3}$ & $\mathbf{\%}$ \\
\hline Mào & 10 & 43.5 \\
\hline Gai & 8 & 34.8 \\
\hline Dây chân & 1 & 4.3 \\
\hline Dây chân + lệch & 1 & 4.3 \\
\hline N & 23 & 100,0 \\
\hline
\end{tabular}

Nhân xét: - Mào và gai vách ngăn gặp nhiều nhất với tỉ lệ lần lượt là $10 / 23$ bệnh nhân chiếm $43.5 \%$, 8/23 bênh nhân chiếm $34.8 \%$.

- Lệch/ vẹo vách ngăn có $3 / 23$ bênh nhân chiếm $13.1 \%$. Loại dị hình chiếm ít nhất là dây chân vách ngăn với $4.3 \%$.

- Có 1 bệnh nhân có loại dị hình phối hợp giữa dày chân vách ngăn với lệch vách ngằn chiếm tỉ lệ $4.3 \%$

3.3 Triệu chứng lâm sàng sau phẫu thuật 24h.

Bảng 3.3: Triệu chứng lâm sàng sau phẫu thuật 24h ( $N=23)$

\begin{tabular}{|c|c|c|}
\hline Triệu chứng cơ năng & $\mathbf{N}$ & $\mathbf{\%}$ \\
\hline Ngạt mũi & 11 & 47,8 \\
\hline Giảm, mất cảm giác ngứi & 0 & 0 \\
\hline U tai, đau tai & 0 & 0 \\
\hline Khô họng/ ho & 1 & 4,3 \\
\hline
\end{tabular}

Nhânn xét: - Ngat mũi là chiệu chứng thường gặp sau phẫu thuật với $11 / 23$ BN chiếm tỉ lệ $47.8 \%$.

- Không có bệnh nhân có triệu chứng tại tai và ảnh hưởng tới chức năng ngứí.

- Có 1 bệnh nhân có triệu chứng khô họng và ho sau phẫu thuật chiếm tỉ lệ $4.3 \%$

Bảng 3.4: Triệu chứng đau sau phẫu thuật 24h ( $N=23)$

\begin{tabular}{|c|c|c|}
\hline Triệu chứng cơ năng & $\mathbf{n}$ & Điểm VAS \\
\hline Đau đâuu & 9 & $1.73 \pm 1.43$ \\
\hline Đau hốc mố & 19 & $2.78 \pm 1.88$ \\
\hline Đau nhức vùng mặt & 12 & $1.91 \pm 1.85$ \\
\hline
\end{tabular}

Nhận xét: - Đau hốc mố gặp nhiều nhất với $19 / 23$ BN, điểm đau trung bình đánh giá theo thang điểm VAS là 2.78 1.88 .

- Đau nhức vùng mặt và đau đầu ít gặp hơn với điểm đau trung bình lần lượt là $1.91 \pm 1.85$ và $1.73 \pm 1.43$.

Bảng 3.5: Kêt quả đánh giá độ thông khí bằng gướng glatzeß ${ }^{\beta}$ mữi bển dị hình $(\mathrm{N}=23)$

\begin{tabular}{|c|c|}
\hline & Sau phâu thuật 24h \\
\hline Ngạt nặng $<3$ & 1 \\
\hline $3 \leq \quad$ Ngạt vừa $<4$ & 12 \\
\hline $4 \leq \quad$ Ngạt nhẹ $<6$ & 10 \\
\hline
\end{tabular}


$6 \leq$ không ngạt <

Thở quá thông $\geq 9$

0

Nhận xét: - Sau phẫu thuật 24h, bệnh nhân được sử dụng merocel có ống thở và được đo mức độ thông khí bằng gương glatzel cho kết quả $100 \%$ thở được qua lỗ thông của merocel. Kết quả ngạt vừa chiếm nhiêu nhất với tỉ lệ $52.2 \%$, ngạt nhẹ $43.5 \%$, có 1 bệnh nhân ngạt năng chiếm tỉ lê $4.3 \%$

- Không có bệnh nhân nào không ngạt, thở quá thông.

\section{Hinh ảnh minh hoa}

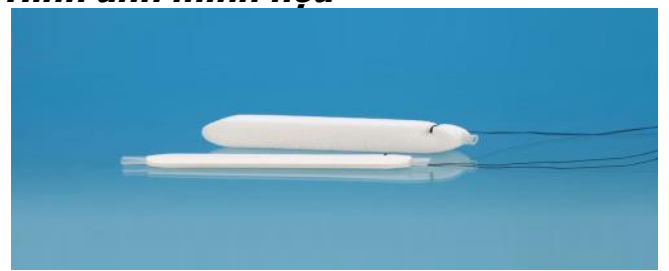

Hinh 3.1 merocel có ông thong

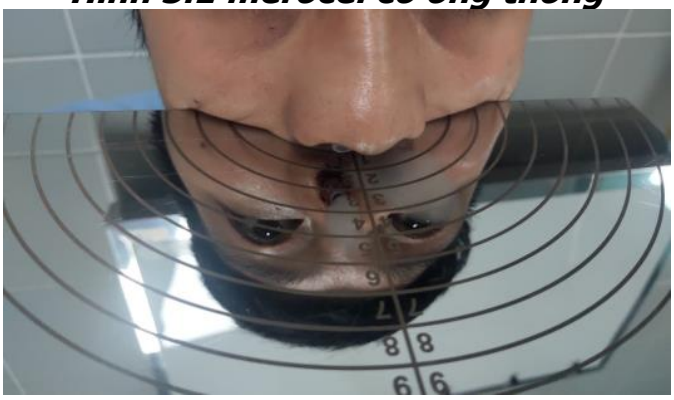

Hình 3.2 Merocel đắt trong mũi

BN Nguyễn Trí T; Số BA: 2105100846 FT ngày 19/5, đo gướng 20/5

3.4. Biến chứng sau phẫu thuật

Bảng 3.6: tỷ lề các biến chứng

\begin{tabular}{|c|c|c|c|}
\hline \multicolumn{2}{|c|}{ Biến chứng } & $\mathbf{N}(\mathbf{n = 2 3})$ & $\mathbf{\%}$ \\
\hline Ngay sau & Chảy máu & 1 & 4.3 \\
\cline { 2 - 4 } phẫu & Nhiếm trùng & 0 & 0 \\
\cline { 2 - 4 } thuật & Tụ máu vách ngăn & 0 & 0 \\
\hline Sau phâ̂u & Thủng vách ngăn & 0 & 0 \\
\cline { 2 - 4 } thuất & Dính niêm mạc & 0 & 0 \\
\cline { 2 - 4 } 1 tháng & Cuộn mép & 2 & 8.6 \\
\hline
\end{tabular}

Nhận xét: - sau phấu thuâat 24h, không gặp bệnh nhân nào biến chứng nhiễm trùng, tụ máu vách ngăn, chỉ có 1 bệnh nhân có chảy máu ra cửa mưi trước mức độ nhẹ chiếm tỉ lệ $4.3 \%$

- Sau phẫu thuật 1 tháng, không gặp bệnh nhân nào thủng vách ngăn, dính niêm mạc. Có 2 bệnh nhân có hiện tượng cuộn mép chiếm tỉ lệ 8.6\%.

\section{BÀN LUÂ̂N}

\subsection{Tuổi và giới}

- Tuổi: đô tuổi trung bình nhóm bênh nhân nghiên cứu là 32.2 tuổi. Nhóm tuổi hay gặp nhất là nhóm tuổi từ 25-35 tuổi, đây là nhóm tuổi lao động. Kết quả này cho thây, dị hình vách ngăn mũi gây rối loạn về hô hấp, ảnh hưởng tới công việc, sinh hoạt, năng suất lao động nên họ tới khám và điều trị nhiều hơn.

- Giới: gặp ở cả nam và nữ, với tỷ lệ nam/nữ $=3.6 / 1$

3.4 Triệu chứng lâm sàng của bệnh nhân trước phẫu thuật. Ngạt mũi là triệu chứng thường gặp nhất trong dị hình vách ngắn chiếm tỷ lệ $91.3 \%(21 / 23)$. Ngạt 1 bên chiếm tỉ lệ $57.1 \%$, ngạt 2 bên chiếm tỉ lệ $42.96 \%$.

Hắt hơi là triệu chứng thường gặp thứ hai chiếm tỷ lệ 82.6\%(19/23), thường là hắt hơi từng tràng, không liên tục.

Chảy mũi gặp ở 18/23BN chiếm tỉ lệ $78.2 \%$, chủ yếu gặp chảy mũi trong, chảy không thường xuyên.

Kết quả này tương đương với nghiên cứu của tác giả Cao Minh Thành ${ }^{4}$, Trân Thị Thanh Thúy ${ }^{3}$. Các nghiên cứu đều chỉ ra rằng, triệu chứng lâm sàng thương gặp do dị hình gây hẹp hốc mũi, ảnh hưởng tới chức năng thông khí và vẩn chuyển chất nhâyy của niêm mạc mũi xoang, từ đó gây ra hiện tượng cương tụ cuốn mũi gây ngạt mũi 1 hoặc cả 2 bên, gây hiện tượng chảy mũi và hắt hơi của bệnh nhân.

Đau đâu chiếm tỳ lệ 34,7\%(8/23), đau đâuu thường âm ì vùng trán gặp nhiêu ở gai vách ngăn phân cao, cơ chế thì nhiêu giả thuyết cho rằng có điểm tiếp xúc giữa vách ngăn với vách mũi xoang, nhất là tiếp xúc phân cao của vách mũi xoang.

Trong dị hình vách ngăn thì hai loại gặp nhiều nhất là mào vách ngăn gặp 10/23 (43.5\%) ,gai vách ngăn gặp 8/23 (34.8\%). Lệch vẹo vách ngăn, dày chân vách ngăn ít gặp trong nghiên cứu ngày, có 1 bệnh nhân có dị dạng phối hợp là dày chân vách ngăn + lệch vách ngăn. Kết quả này tương đồng với kết quả của Trân Thị Thanh Thúy ${ }^{3}$ với $52.1 \%$ và $41.7 \%$ cho 2 loại dị hình là gai vách ngăn và mào vách ngăn.

\subsection{Triệu chứng lâm sàng sau phẫu thuật} 24h. Sau phẫu thuật $24 h$, triệu chứng thường gặp nhất là ngạt mũi gặp ở 11/23 (47.8\%). Đây là triệu chứng chủ quan của người bệnh.

Đánh giá mức độ ngạt mũi bằng gương Glatzel cho kết quả 100\% bệnh nhân thở được qua lỗ thở trên merocel. Với tỉ lệ ngạt nhẹ chiếm $43.5 \%$, ngạt vừa chiếm tỉ lệ $52.2 \%$. chỉ 1 bệnh nhân cho kết quả ngạt nặng với 4.3\%. Kết quả này khác với merocel thông thường khi merocel thông thường gây ngạt tắc lỗ mũi hoàn toàn.

Trong nghiên cứu của tác giả $M$. Sinan Yilmaz ${ }^{5}$ và công sư nghiên cứu về ảnh hưởng chức năng vòi nhĩ ở bệnh nhân được đặt merocel 
mũi sau phẫu thuât. Có tới $73.9 \%$ áp lực tai giữa $<0 \mathrm{daPa}$ (trung bình $-83.13 \pm 58.48$ ). Từ đó gây triệu chứng đau tai, ù tai của bệnh nhân. Tuy nhiên trong nghiên cứu của chúng tôi với cõ mấu nhỏ, triêu chứng khai thác chủ yếu là triêu chứng chủ quan của bệnh nhân, không có bệnh nhân nào có triệu chứng đau tai, ù tai. Kết quả này phần nào cho rằng lố thở ở merocel đảm bảo thông khí tốt, không làm ảnh hưởng tới chức năng thông khí của vòi nhĩ.

Ớ bệnh nhân đặt merocel thông thường, bệnh nhân phải thở bằng miệng. Từ đó dẫn tới triệu chứng của họng như khô họng, ho. Trong nghiên cứu của chúng tôi, với kĩ thuật chỉ đặt merocel có ống thông 1 bên. Có 1 bệnh nhân với tỉ lệ $4.3 \%$ gặp triệu chứng khô họng và ho. Triệu chứng ngày hết sau ngày thứ 2 . Từ đó cho thấy tác dụng của merocel có ống thông, đảm bảo không khí thở được qua mũi, bệnh nhân không phải thở bằng miệng. Không khí được làm ấm, làm ẩm khi đi qua mũi, từ đó tránh được các tác dụng phụ không mong muốn.

Đau sau phầu thuật là triệu chứng chính và khó chịu nhất. Theo tác giả Hesham 6 và cộng sự, điểm đau trung bình bệnh nhân phẫu thuật vách ngăn được đặt merocel thường là 4,73 $\pm 2,05$. Theo tác giả Shengjian Fang ${ }^{7}$ cho kết quả múc độ đau hốc mổ $5.68 \pm 1.31$, đau đâu là $5.88 \pm 1.11$, đau vùng mặt là $6.20 \pm 1.91$ (theo thang điểm VAS). Trong nghiên cứu của chúng tôi, đau hốc mổ gặp ở 19 bệnh nhân với điểm VAS trung bình là 2.78 \pm 1.88 , đau đâu gặp ở 9 bệnh nhân với điểm trung bình là $1.73 \pm 1.43$, và đau nhức vùng mặt là $1.91 \pm 1.85$ gặp ở 12 bệnh nhân. Theo chúng tôi, sự khác biệt này do nhiều yếu tố như:

- Merocel có ống thông giúp bệnh nhân thở được qua đường mũi, làm giảm tác dụng không mong muốn ở họng như trên đã mô tả, từ đó làm bệnh nhân dễ chịu hơn sau mổ, làm giảm cảm giác đau của bênh nhân.

- Kĩ thuật, kinh nghiệm của phẫu thuật viên, tác giả sử dụng khoan vi phẫu tác động trực tiếp lên phần dị hình, bảo tồn tối đa được phần vách ngăn không dị hình.

\subsection{Biến chứng sau phẫu thuâat}

- Sau phẫu thuật, không bệnh nhân nào có biến chứng nhiễm trùng, tụ máu vách ngăn. Có 1 bệnh nhân có triệu chứng chảy máu mức độ nhẹ, và tự hết sau 1 ngày.

- Sau phẫu thuật 1 tháng, không có bệnh nhân nào có biến chứng thủng vách ngăn, dính niêm mạc, kết quả này tương đương với nghiên cứu của tác giả Cao Minh Thành ${ }^{4}$, Trần Thị
Thanh Thúy ${ }^{3}$. Có 2 bệnh nhân có biến chứng cuộn mép, 2 mép niêm mạc có tổ chức vẩy khô, gây chảy máu. bệnh nhân đã được lấy vẩy khô, chăm sóc vết mổ và trạng thái vách ngăn về bình thường sau 2 tuần.

- Chúng tôi cho rằng, merocel có ống thông có chiều dày chưa dãn nở khá lớn $(0.8 \mathrm{~cm})$, nên khi đặt vào hốc mũi sau phẫu thuật ở những bệnh nhân có hốc mũi bé sẽ khó khăn, khó kiểm soát 2 mép niêm mạc từ đó gây ra hiện tượng cuộn mép trên của niêm mạc. Để khắc phục chúng tôi tiến hành khâu 2 mép niêm mạc ở những bệnh nhân có hốc mũi nhỏ, giúp kiểm soát tốt niêm mạc sau khi đặt merocel

\section{KẾT LUẬN}

- Ngạt mũi vừa và nhẹ sau phẫu thuật $24 \mathrm{~h}$ chiếm tỷ lệ 95,7\%.

- Đau hốc mổ có điểm trung bình theo thang điểm VAS là 2.78 1.88 , thấp hơn với nghiên cứu khác có sử dụng merocel thông thường.

- Không có bệnh nhân nào có triệu chứng ở tai: đau tai, ù tai. Chỉ 1 bệnh nhẩn có triệu chứng khô họng và ho chiếm tỉ lệ $4.3 \%$.

- Tai biến thủng vách ngăn, abcess không gặp trường hợp nào

Merocel có ống thông là vật liệu an toàn, làm giảm những triệu chứng khó chịu cho bệnh nhân ngay sau phẫu thuật. Vì vậy, merocel có ống thông nên được sử dụng nhiều hơn trong các phẫu thuật chỉnh hình vách ngăn.

\section{TÀI LIÊU THAM KHẢO}

1. Võ Tấn. Tai Mũi Họng thực hành. Nhà xuất bản y học Thành Phố Hồ Chí Minh,1994.

2. Shah J, Roxbury CR, Sindwani R,Techniques in Septoplasty: Traditional Versus Endoscopic Approaches, Otolaryngologic clinics of North America,2018,51,909-917

3. Trân thị Thanh Thúy, Đánh giá kết quả phẫu thuât di hình vách ngăn bằng khoan microdebrider, Luận văn Thạc sĩ Y học, Trường Đại học Y Hà Nội, 2015,

4. Cao Minh Thành, Phấu thuất nội soi chỉnh hình vách ngăn bằng khoan vi phẩu,Tạp chí Y học Việt Nam,2012,391(1),19-22

5. Yilmaz MS, Guven $M$, Buyukarslan DG, Kaymaz R, Erkorkmaz U, Do silicone nasa septal splints with integral airway reduce postoperative eustachian tube dysfunction?, Otolaryngology--head and neck surgery : official journal of American Academy of OtolaryngologyHead and Neck Surgery,2012,146,141-145

6. Hesham A, Ghali A, Rapid Rhino versus Merocel nasal packs in septal surgery, The Journal of laryngology and otology,2011,125,1244-1246

7. Fang $S$, Wei $X$, Ying $L$, et al., Comparative study of nasal septal retainer and nasal packing in patients undergoing septoplasty, 2019,276,2251-2257 